\title{
Aminoacetone Formation and Utilization by Pseudomonads Grown on DL-1-Aminopropan-2-ol
}

\author{
By I. J. HIGGINS, M. A. PICKARD AND J. M. TURNER \\ Department of Biochemistry, University of Liverpool
}

(Accepted for publication 27 May 1968)

\begin{abstract}
SUMMARY
Pseudomonas sp. 8/1X isolated from soil and Pseudomonas sp. NCIB 8858 are capable of growth on DL-I-aminopropan-2-ol or aminoacetone as sole sources of carbon, nitrogen and energy. During growth on the amino alcohol, small amounts of aminoacetone initially accumulate in the medium but disappear during the early logarithmic phase. Aminoacetone accumulation is favoured by high $\mathrm{pH}$ and high growth-substrate concentrations.

Washed suspensions of the pseudomonads grown on DL-I-aminopropan-2-ol accumulate aminoacetone when incubated with the amino alcohol in the presence of metabolic inhibitors, and rapidly utilize aminoacetone in their absence. Aminoacetone formation is optimal at about $\mathrm{pH}$ io in the presence or absence of the most effective inhibitor iodoacetate.

Aminoacetone utilization occurs optimally at $\mathrm{pH} 7 \cdot 7$, the apparent $K_{m}$ for the amino ketone being about $0.1 \mathrm{mM}$. At an initial concn. of $1.0 \mathrm{mM}$, the rate of utilization is proportional to cell density up to at least $0.5 \mathrm{mg}$. dry wt organisms $/ \mathrm{ml}$. and is constant with time over almost the entire course of the reaction. The maximum rate of utilization is approximately $150 \mathrm{~m} \mu \mathrm{moles} / \mathrm{mg}$. dry wt organisms $/ \mathrm{min}$. at $30^{\circ}$. The phenyl analogue $2^{\prime}$-aminoacetophenone is utilized at a comparable rate but 5-aminolaevulate is virtually unaffected. Anaerobic conditions and metabolic inhibitors prevent amino ketone utilization.

Growth conditions markedly affect the ability of suspensions both to accumulate and utilize aminoacetone. Of the growth substrates tested, only L-threonine enabled Pseudomonas sp. 8/Ix to utilize aminoacetone, the rate being approx. $60 \%$ of that found after growth on DL-I-aminopropan-2-ol

The patterns of oxidation of possible intermediates of DL-I-aminopropan2-ol catabolism are similar using washed organisms grown on either the amino alcohol or aminoacetone. Organisms grown on acetate plus glycine oxidize such compounds at relatively low rates. Methylglyoxal is not a substrate for either growth or oxidation. Comparison of the rates of oxygen uptake and aminoacetone utilization, and measurement of the total oxygen consumed, indicate about $70 \%$ complete oxidation of the amino ketone by organisms grown on the amino alcohol.

Similar maximum crop-sizes are obtained in media in which ammonium sulphate or different relative amounts of D- and L-I-aminopropan-2-ol serve as the sole sources of growth-limiting nitrogen.
\end{abstract}

\section{INTRODUCTION}

Aminoacetone was first isolated as a microbial metabolite of L-threonine by Elliott (1958), who proposed a scheme for its further metabolism via methylglyoxal, D-lactate and pyruvate to acetyl-CoA (Elliott, I959, 1960). Until recently, however, it had not 
been established that aminoacetone was metabolized by micro-organisms at a significant rate (Green \& Elliott, 1964), and suggestions have been made that the amino ketone represents a waste product of no metabolic importance (Neuberger \& Tait, I962; McGilvray \& Morris, I966).

In an attempt to assess the metabolic significance of aminoacetone, micro-organisms have been obtained which are capable of utilizing the amino ketone as a sole source of carbon, nitrogen and energy, for growth. DL-I-aminopropan-2-ol was employed in their isolation by enrichment culture methods. A variety of micro-organisms is known which readily oxidizes the amino alcohol to aminoacetone (Turner, I $966 a$ ) by enzymic dehydrogenation (Turner, 1966 6 , 1967).

Evidence is presented here that pseudomonads grown on DL-I-aminopropan-2-ol metabolize this compound via aminoacetone. Under optimum conditions the amino ketone is metabolized by intact cells at a rapid rate. The work described forms a basis for studies attempting to relate aminoacetone metabolism to microbial physiology and for detailed studies at the enzyme level.

Some of this work has been described in a preliminary communication (Higgins \& Turner, 1966).

\section{METHODS}

Micro-organisms, maintenance and culture. Pseudomonads were isolated from soil samples by the enrichment culture technique using a medium which was also employed. for the culture of these micro-organisms. The medium contained $5 \mathrm{~g}$. DL-I-aminopropan-2-ol: $5 \cdot 4$ g. $\mathrm{KH}_{2} \mathrm{PO}_{4}$ : 0.I g. $\mathrm{MgSO}_{4} \cdot 7 \mathrm{H}_{2} \mathrm{O}$ and I.2 g. $\mathrm{Na}_{2} \mathrm{SO}_{4} \cdot \mathrm{IOH}_{2} \mathrm{O}$ made up to $\mathrm{I}$ l. with distilled water. Media were adjusted to $\mathrm{pH} 7$ with $\mathrm{HCl}$ and sterilized by autoclaving. Other media were prepared in which the amino alcohol was replaced by an equal weight of the compounds indicated in the Results section, or served as the sole source of nitrogen but as a minor source of carbon (I g./1.). Other pseudomonads were obtained from the National Collection of Industrial Bacteria, Aberdeen, Scotland. All micro-organisms were maintained on slopes of nutrient agar $(2.5 \%$ (w/v) Oxoid no. 2 nutrient broth solidified with $\mathrm{x} \cdot 5 \%$ (w/v) Oxoid 'Ionagar' no. 2). Growth on complex natural or simple synthetic media was optimal at $28-30^{\circ}$ and was carried out at $30^{\circ}$. Liquid cultures were incubated on a rotary shaker, usually in 21 . conical flasks containing 11 . of growth medium, for $16-24 \mathrm{hr}$. at $30^{\circ}$.

Preparation of washed suspensions. Cultures were harvested by centrifuging ( $5000 \mathrm{~g}$ for $20 \mathrm{~min}$.), washed with $0 . \mathrm{I} \mathrm{M}$-potassium phosphate buffer $\mathrm{pH} 7 \cdot 0$, and resuspended in the appropriate buffer by homogenizing with a Potter-type tube and pestle.

Measurement of aminoacetone production by washed suspensions. Freshly prepared suspensions in $0 \cdot 1$ M-potassium phosphate buffer, $\mathrm{pH} 7 \cdot 0$, were diluted with the same buffer so that the $E_{540 \mathrm{~m} \mu}^{1 \mathrm{om}}$ for a tenfold diluted sample of the suspension was 0.5 (i.e. $0.17 \mathrm{mg}$. dry wt/ml. diluted sample). Incubation mixtures contained in $\mathrm{I} 0 \mathrm{ml}$., I mmole of phosphate buffer, approx. $5 \mathrm{mg}$. dry wt organisms and $0.5 \mathrm{mmole}$ of DL-I-aminopropan-2-ol adjusted to the appropriate $\mathrm{pH}$ with $\mathrm{HCl}$. Any additions were made up in phosphate buffer and adjusted to $\mathrm{pH} 7.0$ if necessary. Incubations were started by the addition of substrate, and were carried out in $50 \mathrm{ml}$. conical flasks plugged with cotton wool, for $2 \mathrm{hr}$ at $30^{\circ}$ on a rotary shaker. Organisms were removed from suspension by adding $\mathrm{I} \mathrm{ml}$. of $25 \%(\mathrm{w} / \mathrm{v})$ trichloroacetic acid and then centrifuging. Aminoacetone was assayed in I ml. samples of supernatant. Controls were included from which washed organisms or the substrate were omitted. 
Measurement of aminoacetone utilization by washed suspensions. Incubation mixtures contained in Io $\mathrm{ml}$., I mmole of phosphate buffer, $\mathrm{pH} 7 \cdot 0$, about I mg. dry wt organisms and Io $\mu$ moles of aminoacetone. Incubations were started by the addition of freshly washed organisms and were carried out in plugged conical flasks at $30^{\circ}$, with shaking. At timed intervals $\mathrm{I} \mathrm{ml}$. samples were withdrawn and added to $0.3 \mathrm{ml} .25 \%(\mathrm{w} / \mathrm{v})$ trichloroacetic acid. Organisms were removed by centrifuging and $0.1 \mathrm{ml}$. samples of supernatant used for aminoacetone assay. Incubation for I hr. usually resulted in approx. $50 \%$ utilization of the amino ketone. Washed organisms or aminoacetone were omitted from control flasks.

Measurement of oxygen uptake by washed suspensions. Oxygen uptake was measured manometrically in Warburg flasks using conventional procedures. Reaction mixtures contained $100 \mu$ moles phosphate buffer $\mathrm{pH} 7,0.75 \mathrm{mg}$. dry wt organisms and $20 \mu$ moles of substrate in a total volume of $3 \mathrm{ml}$. Manometer readings were made at Io min. intervals over a period of at least $\mathrm{I} \mathrm{hr}$ in all cases.

Assay of aminoacetone. Aminoacetone was determined colorimetrically by the method of Mauzerall \& Granick (1956) as previously described (Turner, 1966).

Measurement of cell density. The density of organisms in both growth and suspension media was measured as the extinction, $E_{540 \mathrm{~m} u}^{\mathrm{lcm}}$, using a Spectrochem spectrophotometer (Hilger and Watts, Ltd., London). Approximate measurements of density were made with an EEL portable colorimeter (Evans Electroselenium Ltd., Halstead, Essex). Calibration curves were used to convert readings to equivalent dry wt organisms $/ \mathrm{ml}$. Extinction values were linear up to an $E_{540 \mathrm{~m} \mu}^{\mathrm{icm}}$ of $2 \cdot \mathrm{I}$, i.e. $0.75 \mathrm{mg}$. dry wt organisms $/ \mathrm{ml}$.

Chemicals. DL-I-Aminopropan-2-ol (i.e. isopropanolamine) was purchased from British Drug Houses Ltd., Poole, Dorset. Optically active preparations of I-aminopropan-2-ol were prepared by the method of Sullivan (1963) as described by Turner (1967). Aminoacetone hydrochloride was synthesized via acetonyl phthalimide (Gabriel \& Pinkus, 1893; Gabriel \& Colman, 1902). D(-)- and L(+)-Lactic acids were obtained as the crystalline solids from Miles Chemical Co., Elkhart, Indiana, U.S.A. Methylglyoxal was purchased as a $30 \%$ aqueous solution from $\mathrm{K}$ and $\mathrm{K}$ Laboratories, Inc., Plainview, New York, U.S.A., and was purified by ion-exchange chromatography (Monder, 1965). $N$-(3-Hydroxybenzyl)- $N$-methylhydrazine phosphate (NSD 1034), was kindly donated by Smith and Nephew Research Ltd., Gilston Park, Harlow, Essex. All other chemicals were of A.R. grade, or the highest quality available commercially.

\section{RESULTS}

Micro-organisms capable of growth on DL-I-aminopropan-2-ol

In addition to the pseudomonads isolated from soil samples (see Methods section) it was found that Pseudomonas sp. NCIB 8858 and NCIB 9397 were capable of growth on DL-I-aminopropan-2-ol. One soil isolate Pseudomonas sp. $8 / \mathrm{IX}$, and one previously characterized pseudomonad (NCIB 8858) were selected for further study.

\section{Factors affecting growth rates and crop size}

It was established that the growth of both the chosen pseudomonads was optimal at about $\mathrm{pH} \mathrm{7,} \mathrm{and} \mathrm{that} \mathrm{the} \mathrm{crop-size} \mathrm{after} \mathrm{growth} \mathrm{for} 24 \mathrm{hr}$ under the conditions described in the Methods section increased with substrate concentration up to about $8 \mathrm{~g}$./1. Small amounts of aminoacetone accumulated in the medium during growth, the 
final amount increasing with initial $\mathrm{pH}$ (from 6.0 to $8 \cdot 0$ ), and growth substrate concentration up to at least $16 \mathrm{~g} . / 1$.

Aminoacetone formation during growth. Preliminary experiments showed that aminoacetone accumulation began immediately following inoculation of fresh DL-Iaminopropan-2-ol medium ( $5 \mathrm{~g}$./1.) with either of the pseudomonads maintained on the same medium, but that the amino ketone was rapidly utilized during the early stages of growth and disappeared towards the end of the logarithmic growth phase. When freshly inoculated cultures of either micro-organism were incubated at $35^{\circ}$, the lag phase of growth was prolonged and the coincidence of aminoacetone utilization with

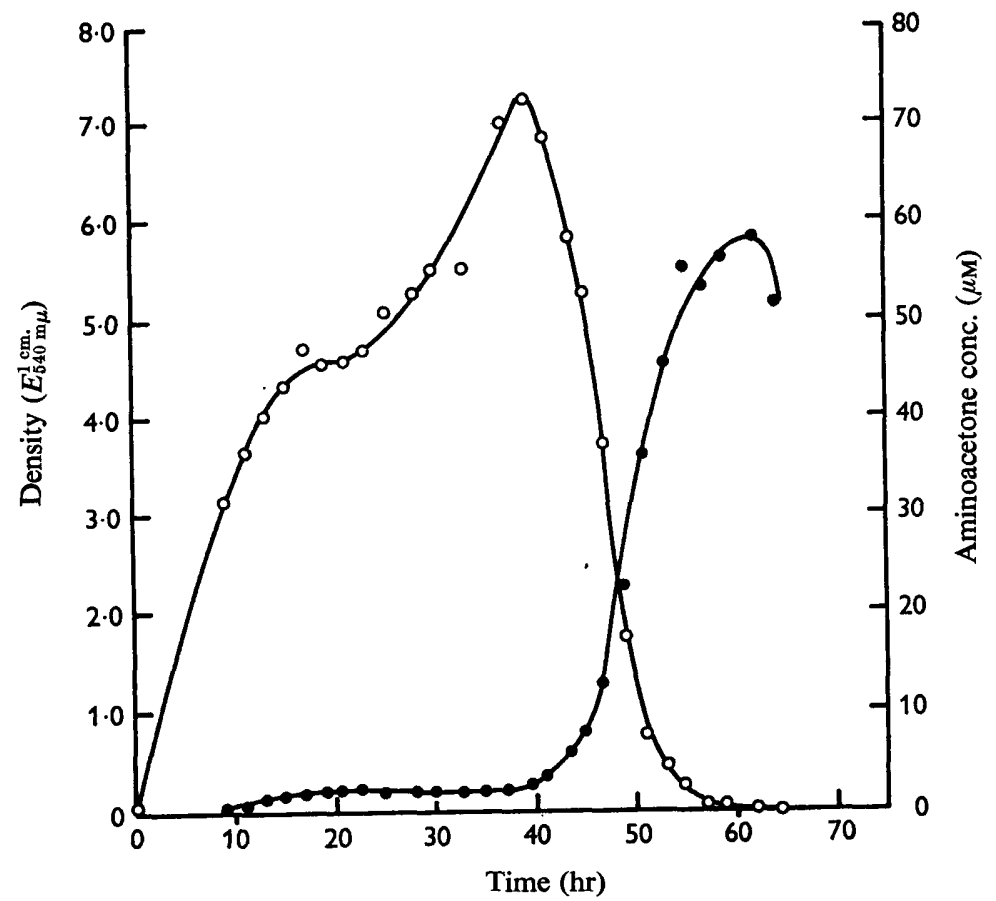

Fig. I. Aminoacetone production and utilization during growth. The Pseudomonas sp. NCIB 8858 was grown on DL-I-aminopropan-2-ol mineral salts medium as described in the Methods sections, except that the growth temperature was $35^{\circ}$. Organism densities (O) and aminoacetone concentrations $(O)$ were measured using a I ml. sample of growth medium rather than suspension, as described in the Methods section.

the onset of logarithmic growth was marked. The results of one experiment are shown in Fig. I. Virtually identical results were obtained with either Pseudomonas sp. NCIB 8858 or $8 / \mathrm{IX}$. In a number of experiments it was noted that the maximum amino acetone concentration in freshly inoculated media never exceeded about $75 \mu \mathrm{M}$, i.e. approximately one-thousandth the initial concentration of DL-I-aminopropan-2-ol.

Factors affecting aminoacetone formation by washed suspensions. When suspensions of amino alcohol-grown Pseudomonas sp. NCIB 8858 were incubated with DL-I-aminopropan-2-ol, very little aminoacetone accumulated. This contrasted with the activity of a variety of other micro-organisms grown on nutrient broth (Turner, I $966 a, b)$, and appeared likely to be due to the further metabolism of the amino ketone. The effect of various factors on aminoacetone formation was investigated. 
Metabolic inhibitors. The effects of a number of metabolites and metabolic inhibitors, used at $\mathrm{pH} 7$ and at different concentrations, are shown in Table I. As can be seen, fluoroacetate, iodoacetate, arsenite, 2,4-dinitrophenol, $N$-(3-hydroxybenzyl)- $N$ methylhydrazine (NSD 1034) and fluoride markedly stimulated aminoacetone accumulation, their effects being commonly more pronounced at high concentrations. A wide variety of metabolites, other than those shown, were found to have no effect on aminoacetone accumulation.

Table I. Effect of various compounds on the production and utilization of aminoacetone by washed suspensions of Pseudomonas sp. NCIB 8858

\begin{abstract}
The pseudomonad was grown on DL-I-aminopropan-2-ol medium and aminoacetone production and utilization at $\mathrm{pH} 7$ and $30^{\circ}$ were measured by standard methods. (See Methods section.) In the absence of any addition the rates of aminoacetone production and utilization were about 0 to $2 \cdot 0$ and $8000 \mathrm{~m} \mu \mathrm{moles} / \mathrm{mg}$. dry wt organisms/hr. respectively.
\end{abstract}

\begin{tabular}{|c|c|c|c|c|c|c|}
\hline \multirow[b]{2}{*}{ Addition } & \multicolumn{3}{|c|}{$\begin{array}{l}\text { Aminoacetone production at } \\
\text { the conc. of addition shown } \\
\text { (m } \mu \text { moles } / \mathrm{mg} \text {. dry wt } \\
\text { organisms } / \mathrm{hr})\end{array}$} & \multicolumn{3}{|c|}{$\begin{array}{l}\text { Aminoacetone utilization at } \\
\text { the conc. of addition shown } \\
\text { (m } \mu \text { moles } / \mathrm{mg} \text {. dry wt } \\
\text { organisms } / \mathrm{hr} \text { ) }\end{array}$} \\
\hline & $25.0 \mathrm{mM}$ & $10.0 \mathrm{mM}$ & $2.0 \mathrm{mM}$ & $10.0 \mathrm{mM}$ & $5.0 \mathrm{mM}$ & $2.5 \mathrm{mM}$ \\
\hline Fluoroacetate & $42 \cdot 0$ & $45 \cdot 8$ & $42 \cdot 0$ & 1420 & 2260 & 2470 \\
\hline Iodoacetate & $39 \cdot 8$ & $21 \cdot 5$ & I6. I & 670 & 730 & I550 \\
\hline Arsenite & $32 \cdot 0$ & $25 \cdot 2$ & $26 \cdot 8$ & 1220 & 920 & 1820 \\
\hline NSD $1034^{*}$ & 30.5 & $28 \cdot I$ & $I \cdot 6$ & $(5750) \dagger$ & $(6330) \dagger$ & $(6800) \dagger$ \\
\hline 2,4-DNP & - & $20 \cdot 2$ & $8 \cdot 2$ & $(4840) t$ & $(5760) \dagger$ & $(6700) \dagger$ \\
\hline Fluoride & 15.6 & $7 \cdot 8$ & $4 \cdot 7$ & 6850 & 6600 & 6650 \\
\hline EDTA & $9 \cdot 6$ & $8 \cdot 3$ & $3 \cdot 6$ & 6200 & 6170 & 6120 \\
\hline Glyoxylate & - & $22 \cdot 8$ & $4 \mathrm{I} \cdot 3$ & 4100 & 3240 & 2060 \\
\hline Glyceraldehyde & - & - & $28 \cdot 3$ & - & - & 7130 \\
\hline Glycolate & $3 I \cdot 0$ & $24 \cdot 8$ & $15 \cdot 2$ & 5010 & 5290 & 5620 \\
\hline Oxaloacetate & 10.4 & $21 \cdot 4$ & 0 & 6310 & 7250 & 7240 \\
\hline Glycine & $7 \cdot 9$ & 4.9 & $3 \cdot 4$ & 5700 & 6010 & 6090 \\
\hline
\end{tabular}

* $N$-(3-hydroxybenzyl)- $N$-methylhydrazine.

$\uparrow$ These results were obtained at one-tenth the concentration of addition indicated.

$p H$. Little aminoacetone accumulation occurred between $\mathrm{pH} 5.5$ and $7 \cdot 0$, but above $\mathrm{pH} 7.5$ aminoacetone levels increased with $\mathrm{pH}$ up to at least $10 \cdot 0$. In the presence of $25 \mathrm{~mm}$-iodoacetate, aminoacetone accumulated at $\mathrm{pH}$ values above 4.0 and increased markedly with $\mathrm{pH}$ above $7 \cdot 0$. These results suggested that whereas the enzyme responsible for amino ketone formation was optimally active at alkaline $\mathrm{pH}$ values, the aminoacetone utilizing system was more active at a $\mathrm{pH}$ closer to neutrality.

\title{
Aminoacetone utilization by resting suspensions
}

The possibility that aminoacetone was an obligatory intermediate in the metabolism of DL-I-aminopropan-2-ol by pseudomonads prompted studies of its utilization.

Preliminary studies showed that the utilization of aminoacetone was rapid after growth on the amino alcohol rather than $\mathrm{L}$-alanine, and that the rate remained constant throughout.

Effect of $p H$. Measurements of aminoacetone utilization at $\mathrm{pH}$ values between $5 \cdot 2$ 
and $9 \cdot 7$ showed that suspensions were optimally active at about $7 \cdot 7$ in potassium phosphate buffer.

Growth phase. The activity of suspensions increased linearly with time during the lag and early logarithmic growth phases, and was maximal in the mid-logarithmic phase. Micro-organisms in the early stationary phase were fully active, and activity was retained for an hour or more after harvesting, washing, and storage as suspensions in phosphate buffer, $\mathrm{pH} 7$, at 0 to $5^{\circ}$.

Effect of aminoacetone concentration. The aminoacetone content of suspension media was followed with time for a range of initial concentrations of the amino ketone. The rate of disappearance was maximal at concentrations above about $0.6 \mathrm{~mm}$, and half-maximal at about $0.1 \mathrm{~mm}$. One consequence of the low apparent Michaelis constant was that in suspension mixtures containing an initial concentration of I.O mM the amount of amino ketone present decreased linearly with time over almost the entire course of the reaction.

Effect of cell density. Under optimum conditions, the initial rate of aminoacetone utilization was linear with organism density up to at least $0.5 \mathrm{mg}$. dry wt organisms per ml. With freshly harvested Pseudomonas sp. NCIB 8858 or $8 / \mathrm{IX}$, the rate of disappearance of the amino ketone was frequently as high as $150 \mathrm{~m} \mu \mathrm{moles} / \mathrm{mg}$. dry wt organisms/min.

Effect of anaerobiosis. In all the experiments described above, suspension mixtures were incubated aerobically with shaking. The effect of incubating aerobically in nonshaken flasks, and anaerobically under an atmosphere of oxygen-free nitrogen, was to reduce activity by about 65 and $90 \%$ respectively.

Specificity of amino ketone utilization. The phenyl analogue 2 -aminoacetophenone was removed from suspension mixtures at $58 \%$ of the rate observed with aminoacetone. Another metabolically active amino ketone 5-aminolaevulic acid (Shemin \& Russell, 1953; Neuberger \& Scott, 1953) was utilized at a relative rate of only $6 \%$. Pseudomonas sp. NCIB 8858 was used in this work.

Effect of metabolic inhibitors and intermediates. The effects of common metabolic inhibitors on aminoacetone utilization are shown in Table I. It can be seen that in general the most effective inhibitors were those which were active in stimulating the accumulation of the amino ketone when suspensions were incubated with DL-I-aminopropan-2-ol. It should be noted that even in the presence of the most effective inhibitors used at $10 \mathrm{~mm}$, the rate of aminoacetone utilization greatly exceeded its rate of production from the amino alcohol.

Effect of growth conditions. When Pseudomonas sp. NCIB 8858 was grown on media in which DL-I-aminopropan-2-ol served as the sole source of nitrogen but other compounds served as the major source of carbon, rates of aminoacetone utilization were usually decreased, as shown in the first part of Table 2. When Pseudomonas sp. 8/1X was grown on L-threonine as sole source of carbon and nitrogen, suspensions utilized aminoacetone at approximately $60 \%$ the rate observed after growth on DL-Iamino-propan-2-ol. Pseudomonas sp. NCIB 8858 was incapable of growth on the amino acid. Growth on a mixture of acetate and glycine yielded cells with virtually no amino-acetone utilizing ability.

Evidence on the nature of pathways possibly involved in the metabolism of DL-I-aminopropan-2-ol and aminoacetone. Both pseudomonads were found to be capable of vigorous growth on a simple synthetic medium in which aminoacetone replaced the 
amino alcohol. This medium was adjusted to $\mathrm{pH} 6 \cdot 7$ to minimise chemical decomposition of the amino ketone. Vigorous growth of Pseudomonas sp. NCIB 8858 also occurred on media containing DL-lactate or pyruvate as sole carbon sources with $\left(\mathrm{NH}_{4}\right)_{2} \mathrm{SO}_{4}$ as the nitrogen source. No growth occurred on similar media in which methylglyoxal

\section{Table 2. Effect of growth conditions on the ability of washed suspensions of Pseudomonads to utilize aminoacetone}

Rates of aminoacetone utilization were measured as described in the Methods section. The results in the first part of the table were obtained with Pseudomonas sp. NCIB 8858 grown on the compounds shown (4 g./l.) as major sources of carbon, with DL-I-aminopropan-2-ol (I g./l.) as sole source of nitrogen. Media were otherwise as described in the Methods section. Results in the second part of the table were obtained with Pseudomonas sp.8/1X grown on the compounds shown as sole sources of carbon and nitrogen ( $5 \mathrm{~g} . / 1$.$) .$

$\begin{array}{ccc}\text { Pseudomonad used } & \begin{array}{c}\text { Major or sole source of carbon } \\ \text { in growth medium }\end{array} & \begin{array}{c}(\mathrm{m} \mu \mathrm{moles} / \mathrm{mg} . \\ \text { dry wt } \\ \text { organisms/hr) }\end{array} \\ \text { NCIB 8858 } & \begin{array}{c}\text { DL-I-Aminopropan-2-ol } \\ \text { 2-Oxoglutaric acid }\end{array} & 4200 \\ \text { Pyruvic acid } & 2730 \\ \text { DL-Lactic acid } & 4200 \\ \text { Succinic acid } & 2900 \\ \text { Citric acid } & 3190 \\ & \text { Sucrose } & 2180 \\ \text { Maltose } & 5120 \\ \text { 8/IX } & \text { DL-I-Aminopropan-2-ol } & 2140 \\ & \text { L-Threonine } & 4450 \\ \text { DL-Alanine } & 2840 \\ & & 430\end{array}$

Aminoacetone utilization m $\mu$ moles/mg. organisms/hr)

Table 3. Oxidation of substrates by washed suspensions of Pseudomonas sp. 8858 grown on various media

The pseudomonad was grown on the compounds shown as sole sources of carbon and nitrogen $(5 \mathrm{~g} . / \mathrm{ml}$.), in media otherwise the same as described in the Methods section.

\begin{tabular}{|c|c|c|c|}
\hline \multirow[b]{2}{*}{ Substrate oxidized } & \multicolumn{3}{|c|}{$\begin{array}{c}Q_{\mathrm{O}_{2}} \text { (corrected for endogenous), after growth } \\
\text { on the compounds shown. ( } \mu \text { moles oxygen } \\
\text { absorbed/mg. dry wt organisms/hr.) }\end{array}$} \\
\hline & $\begin{array}{l}\text { DL-I-amino- } \\
\text { propan-2-ol }\end{array}$ & $\begin{array}{l}\text { Amino- } \\
\text { acetone }\end{array}$ & $\begin{array}{l}\text { Acetate plus } \\
\text { glycine }\end{array}$ \\
\hline $\begin{array}{l}\text { DL-I-Aminopropan-2-ol } \\
\text { L-I-Aminopropan-2-ol } \\
\text { Aminoacetone } \\
\text { L-Lactate } \\
\text { D-Lactate } \\
\text { Pyruvate }\end{array}$ & $\begin{array}{r}11 \cdot 4 \\
9 \cdot 1 \\
9 \cdot 3 \\
13 \cdot 5 \\
6 \cdot 0 \\
9 \cdot 9\end{array}$ & $\begin{array}{l}8 \cdot 4 \\
8 \cdot 2 \\
6 \cdot 7 \\
6 \cdot 1 \\
3 \cdot 8 \\
6 \cdot 7\end{array}$ & $\begin{array}{l}1 \cdot 7 \\
2 \cdot 4 \\
2 \cdot 2 \\
3 \cdot 6 \\
2 \cdot 6 \\
5 \cdot 2\end{array}$ \\
\hline Endogenous correction & $I \cdot 3$ & $\mathbf{x} \cdot 3$ & $2 \cdot 3$ \\
\hline
\end{tabular}

was used at concentrations of 0.2 to $5.0 \mathrm{~g} . / 1$. as the sole carbon source. Methylglyoxal completely inhibited growth on DL-I-aminopropan-2-ol medium when added at concentrations above $10 \mathrm{~mm}(0.72 \mathrm{~g}$./1.), but was not inhibitory at 0.1 to $2.0 \mathrm{~mm}$.

Oxidation of possible intermediates by suspensions grown on various substrates. 
Washed suspensions of Pseudomonas sp. NCrB 8858 grown on DL-I-aminopropan-2-ol, aminoacetone or an equimolar mixture of acetate and glycine, oxidized possible catabolites of the amino alcohol as shown in Table 3. Under the conditions used methylglyoxal was not oxidized by any of the suspensions. All other substrates were oxidized without any appreciable lag. In general the pattern of oxidation of substrates was similar for organisms grown on either DL-I-aminopropan-2-ol or aminoacetone. Organisms grown on acetate plus glycine oxidized the amino alcohol and ketone at relatively low rates. Separate experiments showed that suspensions grown on either DL-lactate or pyruvate, with $\left(\mathrm{NH}_{4}\right)_{2} \mathrm{SO}_{4}$ as nitrogen source, were virtually incapable of oxidizing the amino alcohol or ketone. When organisms were grown on DL-Iaminopropan-2-ol the rate of oxygen uptake with aminoacetone was equivalent to the total oxidation of $100 \mathrm{~m} \mu$ moles $/ \mathrm{mg}$. dry wt organism $/ \mathrm{ml}$. When oxygen uptake was compared with aminoacetone utilization, measured colorimetrically, the results indicated about $70 \%$ complete oxidation of the amino ketone. The total oxygen absorbed during oxidation of $5 \mu$-mole aminoacetone also corresponded to $70 \%$ complete oxidation.

Growth on optically active preparations of I-aminopropan-2-ol. The maximum cropsize of cultures grown on succinate $(5 \mathrm{~g} . / 1$.), with limiting amounts of racemic or partially resolved preparations of I-aminopropan-2-ol, or $\left(\mathrm{NH}_{4}\right)_{2} \mathrm{SO}_{4}(5 \mathrm{mg}$. N/1.) was measured turbidimetrically. The results showed that the yield of organisms was virtually independent of the relative amounts of the $D(-)$ - and $\mathrm{L}(+)$-isomers of the amino alcohol ( 17 to $75 \% \mathrm{D}(-)$-isomer present) and was somewhat greater than when $\left(\mathrm{NH}_{4}\right)_{2} \mathrm{SO}_{4}$ served as the source of nitrogen. Similar results were obtained using the bacterium Erwinia carotovora (J. M. Turner, unpublished work).

\section{DISCUSSION}

The fact that pseudomonads capable of growth on DL-I-aminopropan-2-ol can also grow on aminoacetone suggests that the compound is an intermediate during growth on the amino alcohol. This is supported by the observation that the aminoacetone which initially accumulates in freshly inoculated medium is rapidly utilized as soon as growth begins. Similarly, inhibitors of aminoacetone utilization stimulate its accumulation, and similar rates of oxygen uptake are observed when organisms grown. on the amino alcohol are incubated with either the growth substrate or aminoacetone.

It is now known that the mechanism of aminoacetone formation by Pseudomonas sp. NCIB 8858 involves an L-I-aminopropan-2-ol:NAD oxidoreductase (Pickard, Higgins \& Turner, 1966, 1968). The properties of this enzyme are consistent with the rapid oxidation of the amino alcohol to aminoacetone by washed suspensions at $\mathrm{pH}$ 10. The mechanism of D-I-aminopropan-2-ol utilization is unknown.

Part of the work described here represents the first unambiguous demonstration that certain micro-organisms can metabolize aminoacetone (Higgins \& Turner, 1966). It was previously pointed out by Green \& Elliott (1964) that although preparations of some micro-organisms showed slight activity towards the amino ketone, its further metabolism at a significant rate had yet to be established. The recently reported metabolism of aminoacetone by a micro-organism similar to Arthrobacter globiformis, after growth on L-threonine (Green \& Lewis, 1968), occurs at a rate only $5 \%$ of those described here for pseudomonads. 
Preliminary evidence on the enzymic mechanism of aminoacetone utilization indicates that a coupled aminotransferase and 2-oxoaldehyde-NAD ${ }^{+}$oxidase (Monder, 1965, 1967) system may be involved (Higgins, Turner \& Willetts, 1967).

Only tentative conclusions on the route of aminoacetone catabolism may be drawn from the work described here. Growth and substrate oxidation studies give results consistent with the oxidation of exogenous or endogenous aminoacetone via lactate and pyruvate (Elliott, 1959, 1960), but no indication of a role for methylglyoxal. It is possible that this 2-oxoaldehyde is an intermediate but that intact organisms are either impermeable or incapable of oxidizing it at the concentration tested. It is of interest that Green \& Lewis (1968) have demonstrated the production of methylglyoxal from aminoacetone by suspensions of an Arthrobacter sp.

Substrate oxidation studies with organisms grown on a mixture of acetate and glycine indicate that glycine is not metabolized via the aminoacetone cycle proposed by Elliott (1959, 1960). The utilization of aminoacetone by suspensions of Pseudomonas sp. 8/IX grown on L-threonine indicates that the amino acid may be partly catabolized via the amino ketone by this micro-organism.

The general metabolic roles of I-aminopropan-2-ol and aminoacetone are uncertain, although a number of suggestions have been put forward (Neuberger \& Tait, 1960; Neuberger, 196I; Turner, I966 b, 1967; Turner \& Willetts, 1967).

The interest and support of Professor T. W. Goodwin in this work is gratefully acknowledged. The authors thank Miss E. Duggan for expert technical assistance. We are grateful to Dr M. Goodfellow for the identification of one of the pseudomonads. The work of I.J.H. and M.A.P. was supported by grants from the Medical Research Council and the University of Liverpool respectively.

\section{REFERENCES}

Elliot,, W. H. (1958). A new threonine metabolite. Biochem biophys. Acta 29, 446.

Elliort, W. H. (1959). Aminoacetone. Its isolation and role in metabolism. Nature, Lond. 183, $105 \mathrm{I}$. ElliotT, W. H. (1960). Aminoacetone formation by Staphylococcus aureus. Biochem. J. 74, 478.

Gabriel, S. \& Colman, J. (1902). Zur Kenntrias der Amidoacetons. Ber. dt. chem. Ges. 35, 3805.

Gabriel, S. \& Pinkus, G. (1913). Zur Kenntrias der Amidoketone. Ber. dt. chem. Ges. 26, 2197.

GreEN, M. L. \& ElLIOTT, W. H. (1964). The enzymic formation of aminoacetone from threonine and its further metabolism. Biochem. J. 92, 537.

Green, M. L. \& LEWIS, J. B. (I968). The oxidation of aminoacetone by a species of Arthrobacter. Biochem. J. 106, 267.

Higgins, I. J., \& TURner, J. M. (I966). Microbial metabolism of aminoacetone. Biochem. J. 99, 26 P.

Higgins, I. J., TuRner, J. M. \& WilletTs, A. J. (1967). Enzyme mechanism of aminoacetone metabolism by micro-organisms. Nature, Lond. $2 \mathbf{r}_{5}, 887$.

MaUzerall, D. \& Granick, S. (1956). The occurrence and determination of 5-aminolevulinic acid and porphobilinogen in urine. J. biol. Chem. 219, 435 .

MCGILVRAY, D. \& MorRIs, J. G. (1966). The metabolic fate of $\alpha$-amino- $\beta$-oxobutyrate in Arthrobacter sp. Biochem. J. 99, I 2 P.

MONDER, C. (1965). Oxidation of methyl glyoxal to pyruvic acid by a sheep-liver enzyme. Biochem. biophys. Acta 99, 573.

MONDER, C. (1967). $\alpha$-Ketoaldehyde dehydrogenase: an enzyme that catalyses the enzymic oxidation of methylglyoxal to pyruvate. J. biol. Chem. 242, 4603 .

Neuberger, A. (196I). Aspects of the metabolism of glycine and of porphyrins. Biochem. J. 78, 1 .

NeUberger, A. \& ScotT, J. J. (1953). Aminolaevulinic acid and porphyrin biosynthesis. Nature, Lond. 172, I093. 
NeUBERgER, A. \& TAIT, G. H. (1960). The enzymic conversion of threonine to aminoacetone. Biochem. biophys. Acta 4I, 164.

NeUBERGER, A. \& TAIT, G. H. (1962). Production of aminoacetone by Rhodopseudomonas spheroides. Biochem. J. 84, 317.

Pickard, M. A. \& TuRner, J. M. (1966). Microbial metabolism of 5-aminolaevulate. Biochem. J. 99, 25 P.

Pickard, M. A., Higgins, I. J. \& TURner, J. M. (I966). Microbial Metabolism of I-Aminopropan2-ol. J. gen. Microbiol. 45, i.

Pickard, M. A., Higgins, I. J. \& Turner, J. M. (I968). Purification and properties of L-Iaminopropan-2-ol: NAD oxidoreductase from a pseudomonad grown on DL-I-aminopropan-2-ol J. gen. Microbiol. 54, 115.

SHEMIN, D. \& Russell, C. S. (1953). $\delta$-Aminolevulinic acid, its role in the biosynthesis of porphyrins and purines. J. Am. chem. Soc. 75,4873 .

Sullivan, R. H. (1963). Resolution of racemic aminoisopropanol. U.S. Patent, 3, I16, 332 (Cl. 260-584).

TURNER, J. M. (1966a). Aminoacetone production by micro-organisms. Biochem. J. 98, 7 P.

TURNER, J. M. (1966 b). Microbial metabolism of aminoketones. Aminoacetone formation from I-aminopropan-2-ol by a dehydrogenase in Escherichia coli. Biochem. J. 99, 427.

TURNER, J. M. (1967). Microbial metabolism of aminoketones. L-I-Aminopropan-2-ol and L-threonine dehydrogenase in Escherichia coli. Biochem. J. x04, I 12.

TURNER, J. M. \& WILLETTS, A. J. (I967). Aminoketone formation and aminopropanol-dehydrogenase activity in rat-liver preparations. Biochem. $J$. 102, $5 \mathrm{II}$. 